\title{
Alcohol intake and ovarian cancer risk: a pooled analysis of 10 cohort studies
}

\begin{abstract}
JM Genkinger, I, DJ Hunter 1,2,3 , D Spiegelman ${ }^{2,4}$, KE Anderson ${ }^{5}$, JE Buring ${ }^{2,6}$, JL Freudenheim ${ }^{7}$, RA Goldbohm $^{8}$, L Harnack ${ }^{5}$, SE Hankinson ${ }^{2,3}$, SC Larsson', M Leitzmann ${ }^{10}$, ML McCullough '1, J Marshall ${ }^{7}$, AB Miller ${ }^{12}$, C Rodriguez ", TE Rohan ${ }^{13}$, A Schatzkin ${ }^{10}$, LJ Schouten ${ }^{14}$, A Wolk9, SM Zhang ${ }^{2,6}$ and SA Smith-Warner,2

'Department of Nutrition, Harvard School of Public Health, Boston, MA, USA; ${ }^{2}$ Department of Epidemiology, Harvard School of Public Health, Boston, MA, USA; ${ }^{3}$ Channing Laboratory, Department of Medicine, Brigham and Women's Hospital and Harvard Medical School, Boston, MA, USA; ${ }^{4}$ Department of Biostatistics, Harvard School of Public Health, Boston, MA, USA; ${ }^{5}$ Division of Epidemiology, School of Public Health, University of Minnesota, Minneapolis, MN, USA; ${ }^{6}$ Division of Preventive Medicine, Department of Medicine, Brigham and Women's Hospital and Harvard Medical School, Boston, MA, USA; ${ }^{7}$ Department of Social and Preventive Medicine, University at Buffalo, State University of New York, Buffalo, NY, USA; ${ }^{8}$ Department of Food and Chemical Risk Analysis, TNO Quality of Life, Zeist, The Netherlands; ${ }^{9}$ Division of Nutritional Epidemiology, National Institute of Environmental Medicine, Karolinska Institute, Stockholm, Sweden; ${ }^{10}$ Division of Cancer Epidemiology and Genetics, National Cancer Institute, NIH, DHHS, Bethesda, MD, USA; "'Epidemiology and Surveillance Research, American Cancer Society, Atlanta, GA, USA; ${ }^{12}$ Department of Public Health Sciences, Faculty of Medicine, University of Toronto, Toronto, Ontario, Canada; ${ }^{13}$ Department of Epidemiology and Population Health, Albert Einstein College of Medicine, Bronx, NY, USA; ${ }^{14}$ Department of Epidemiology, NUTRIM, Maastricht University, Maastricht, The Netherlands
\end{abstract}

\begin{abstract}
Alcohol has been hypothesized to promote ovarian carcinogenesis by its potential to increase circulating levels of estrogen and other hormones; through its oxidation byproduct, acetaldehyde, which may act as a cocarcinogen; and by depletion of folate and other nutrients. Case-control and cohort studies have reported conflicting results relating alcohol intake to ovarian cancer risk. We conducted a pooled analysis of the primary data from ten prospective cohort studies. The analysis included 529638 women among whom 200 I incident epithelial ovarian cases were documented. After study-specific relative risks (RR) and $95 \%$ confidence intervals (Cl) were calculated by Cox proportional hazards models, and then were pooled using a random effects model; no associations were observed for intakes of total alcohol (pooled multivariate $\mathrm{RR}=1.12,95 \% \mathrm{Cl} 0.86-1.44$ comparing $\geqslant 30$ to $0 \mathrm{~g}$ day ${ }^{-1}$ of alcohol) or alcohol from wine, beer or spirits and ovarian cancer risk. The association with alcohol consumption was not modified by oral contraceptive use, hormone replacement therapy, parity, menopausal status, folate intake, body mass index, or smoking. Associations for endometrioid, mucinous, and serous ovarian cancer were similar to the overall findings. This pooled analysis does not support an association between moderate alcohol intake and ovarian cancer risk.
\end{abstract}

British Journal of Cancer (2006) 94, 757-762. doi: I0.1038/sj.bjc.6603020 www.bjcancer.com

Published online 21 February 2006

(c) 2006 Cancer Research UK

Keywords: alcohol; ovarian cancer; pooled analysis

Alcohol intake has been associated with a higher risk of cancers of the upper alimentary tract, liver, large intestine, and breast (Poschl and Seitz, 2004). Alcohol has been theorized to promote carcinogenesis by its potential to increase circulating levels of oestrogen and other hormones; through its oxidation byproduct, acetaldehyde, which may act as a cocarcinogen; by induction of cytochrome P450 enzymes which are involved in the activation of liver carcinogens; and by depletion of folate (Poschl and Seitz, 2004). In contrast, alcohol has also been hypothesized to prevent ovarian carcinogenesis by decreasing follicle stimulating hormone

*Correspondence: Dr JM Genkinger;

E-mail: pooling@hsphsun2.harvard.edu

Institution where work was performed: Harvard School of Public Health, Boston, MA, USA

Received 17 November 2005; revised 16 January 2006; accepted 30 January 2006; published online 2I February 2006
(Gavaler and van Thiel, 1992), luteinizing hormone (Gavaler and van Thiel, 1992) and gonadotropins (Verkasalo et al, 2001) levels, all of which have been hypothesized to increase ovarian cancer risk (Cramer and Welch, 1983).

Several epidemiologic studies have examined the association between alcohol consumption and ovarian cancer risk (McCann et al, 2003; Modugno et al, 2003; Kelemen et al, 2004; Larsson et al, 2004; Riman et al, 2004; Webb et al, 2004). A recent meta-analysis reported a $30 \%$ lower risk of ovarian cancer risk with higher intakes of alcohol (Webb et al, 2004) for population based casecontrol and cohort studies, but found no association for hospitalbased case-control studies. Overall, the results from cohort studies of women with alcoholism have been nonstatistically significant, with suggestions of positive and inverse associations between alcohol intake and ovarian cancer risk (Webb et al, 2004). One of two case-control studies has found that alcohol intake was positively associated with risk of mucinous tumours (Kuper et al, 2000; Modugno et al, 2003). 
Owing to the potential for recall bias in case-control studies and the small number of cases in most cohort studies, we investigated the associations between alcohol intake and ovarian cancer risk in a pooled analysis of several prospective studies. As the effect of alcohol may vary by potential ovarian cancer risk factors, we also considered whether the association differed by hormonal, environmental and nutritional factors. We also examined associations separately for endometrioid, mucinous, and serous ovarian cancers.

\section{MATERIALS AND METHODS}

\section{Population}

A pooled analysis of the primary data from 10 prospective cohort studies (Bandera et al, 1997; Rockhill et al, 1998; Bertone et al, 2002; Calle et al, 2002; Lacey et al, 2002; Terry et al, 2003; Kelemen et al, 2004; Larsson et al, 2004; Lin et al, 2004; Schouten et al, 2004) was conducted in The Pooling Project of Prospective Studies of Diet and Cancer (Table 1). To be included in this analysis, each study needed a minimum of 50 incident ovarian cancer cases, an assessment of usual diet, including alcohol intake, and validation of the dietary assessment tool or a closely related instrument.

Two studies, the Canadian National Breast Screening Study and Netherlands Cohort Study, were analysed as case-cohort studies because the investigators have processed questionnaires for newly diagnosed cases and a random sample of noncases to represent the person-time of the entire study population. The follow-up of the Nurses' Health Study was divided into two sections where NHS (a) followed individuals from the completion of the 1980 food frequency questionnaire (FFQ) to 1986, and NHS (b) followed those individuals still at risk from the completion of the $1986 \mathrm{FFQ}$ (a more comprehensive FFQ compared to the 1980 questionnaire) to 2002. The methods for the Pooling Project have been described in detail elsewhere (Smith-Warner et al, in press).

\section{Exclusions}

In addition to applying the exclusions that each study had predefined for their cohort, we excluded individuals if they had a prior cancer diagnosis other than nonmelanoma skin cancer at baseline, had a bilateral oophorectomy prior to baseline, had $\log _{\mathrm{e}}$ transformed energy intakes beyond 3 s.d. from the study-specific $\log _{\mathrm{e}}$-transformed mean energy intake of their respective population, or had missing alcohol intake data. The New York State Cohort (Bandera et al, 1997) did not obtain information on oophorectomy at baseline, and thus we were not able to apply that exclusion there.

\section{Exposure assessment}

Usual dietary intake was estimated at baseline from study-specific FFQs. All studies, except the New York State Cohort, measured alcohol intake from wine, beer, and spirits (see Table 1). In these studies, daily alcohol intake in grams was calculated for each beverage based on the reported frequency of consumption, the alcohol content of the beverage, and the average quantity consumed. The alcohol intake from each specific beverage was summed to estimate total alcohol intake. Intakes of other nutrients were estimated using a similar approach. In the New York State Cohort, the 'regression weight' method was used to estimate nutrient and alcohol values (Bandera et al, 1997). Correlations between energy-adjusted alcohol intake measured from the studyspecific FFQ or a closely related instrument and multiple $24 \mathrm{~h}$ recalls or food records generally exceeded 0.77 for total alcohol intake (Giovannucci et al, 1991; Munger et al, 1992; Goldbohm et al, 1994; Flagg et al, 2000; Wolk et al, personal communication).

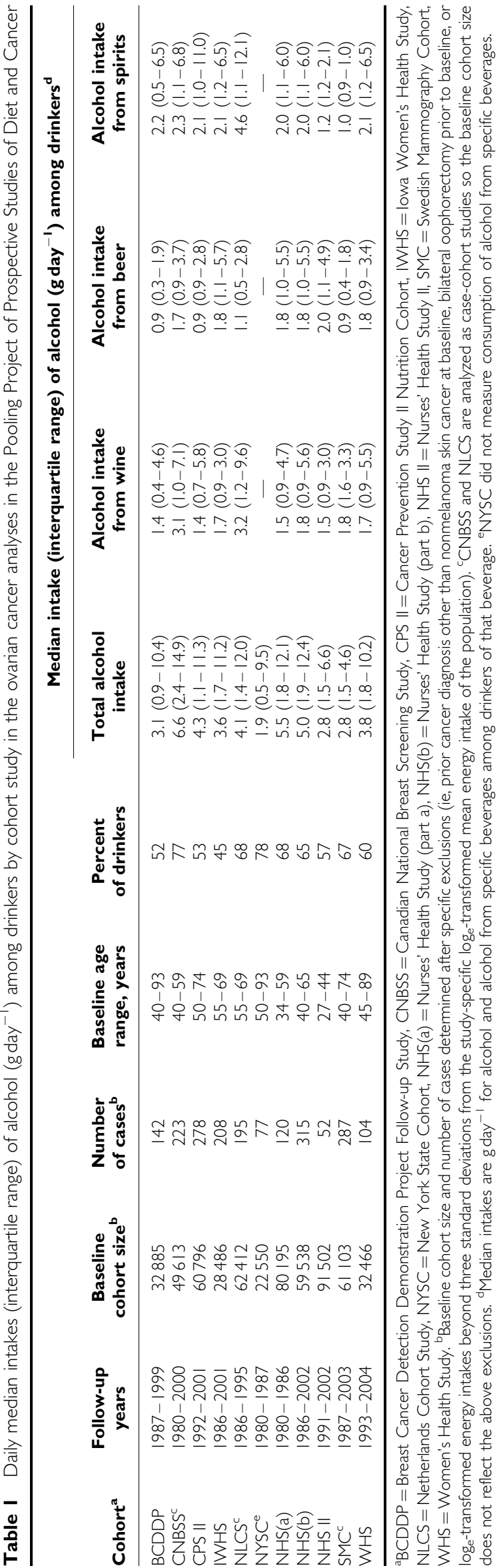

(c) 2006 Cancer Research UK 
Information on nondietary factors was collected on the baseline self-administered questionnaires within each study. Most studies obtained information on multiple reproductive factors, body mass index, smoking status, and physical activity.

\section{Outcome assessment}

Participants were followed from the date of the baseline questionnaire until date of ovarian cancer diagnosis, date of death, date the participant moved out of the study area (if applicable), or end of follow-up, whichever came first. Invasive epithelial ovarian cancer, defined by ICD-9 code 183.0 or ICD-10 code C56, was ascertained by self-report with subsequent medical record review, cancer registry linkage, or both. Some studies additionally obtained information from death registries (SmithWarner et al, in press). Borderline and nonepithelial ovarian cancer cases, as determined by International Classification of Diseases for Oncology morphology codes (Percy et al, 1990) or the histological information supplied by individual studies, were not included as cases.

\section{Statistical analysis}

Alcohol intake was modelled categorically within each individual study using identical absolute cutpoints. Studies were excluded from the analysis if they did not measure intake of that specific beverage or if that beverage was not consumed in that population.

Relative risks (RR) and 95\% confidence intervals (CI) were calculated by Cox proportional hazards models (Cox, 1972) for each study. The models included stratification by age (years) at baseline and the calendar year at start of follow-up, and treated follow-up time (years) as the time scale. Multivariate relative risks were adjusted for age at menarche, menopausal status at baseline, oral contraceptive use, hormone replacement therapy use among postmenopausal women, parity, body mass index, smoking status, physical activity, and energy intake, modelled identically across studies. An indicator variable for missing values was also generated within a study for each covariate, if applicable (SmithWarner et al, in press). To test whether there was a linear trend in the risk of disease with increasing alcohol intake, a continuous variable with values corresponding to the median value for each exposure category was included in the model; the coefficient for that variable was evaluated using the Wald test. SAS software (Allison, 1995) was used for the cohort analyses, and Epicure software (1993) was used for the case-cohort analyses.

Study-specific relative risks were pooled using a random effects model (DerSimonian and Laird, 1986). The study-specific relative risks were weighted by the inverse of the sum of their variance and the estimated between-studies variance component. Betweenstudies heterogeneity was evaluated using the Q statistic (Cochran, 1954; DerSimonian and Laird, 1986).

We also tested whether the associations for alcohol from beer, wine, and liquor and ovarian cancer risk differed by using a contrast test for the pooled estimates for each beverage and their covariance matrix from the random-effects model. The test statistic followed approximately a $\chi^{2}$ distribution with 2 degrees of freedom (Anderson, 1984). For each study, we corrected the relative risk for total alcohol intake for measurement error using the regression coefficients between alcohol intakes estimated by the FFQs and reference methods (Rosner et al, 1989, 1990).

We also evaluated whether alcohol intake was linearly associated with ovarian cancer risk by comparing nonparametric regression curves using restricted cubic splines to the linear model using the likelihood ratio test, and by visual inspection of the restricted cubic spline graphs (Smith, 1979; Durrleman and Simon, 1989). The studies were combined into a single data set, and analysed as above, additionally stratified by study. Owing to the small numbers of individuals consuming high amounts of alcohol, this analysis was limited to women consuming $<60 \mathrm{~g} \mathrm{day}^{-1}$ of alcohol.

Further analyses were conducted to examine whether the association between alcohol consumption and ovarian cancer risk varied by hormonal, environmental and nutritional factors. As most studies collected information at baseline only, for analyses evaluating whether menopausal status modified the association between alcohol consumption and ovarian cancer risk, we assigned menopausal status at follow-up in each study using a previously described algorithm (Smith-Warner et al, 1998). For each factor, an interaction term between the level of each factor and alcohol intake expressed as a continuous variable was included in the model. Participants with missing values of the modifying factor were excluded from these analyses. Separate analyses were also conducted for endometrioid, mucinous, and serous subtypes among those studies having more than 10 cases of the specific subtype. Subtype analyses were conducted among these three histologies since they are the three most common, representing $68 \%$ of all ovarian cancer cases in our population. We tested whether results differed across the subtypes using a contrast test (Anderson, 1984).

\section{RESULTS}

The total study population consisted of 529638 women among whom 2001 developed invasive epithelial ovarian cancer over 4.6 million person years (Table 1). The percentage of alcohol drinkers in each study ranged from 45 to $78 \%$. Median total alcohol intake among drinkers was low and ranged from 1.9 to $6.6 \mathrm{~g} \mathrm{day}^{-1}$.

Alcohol intake was not associated with ovarian cancer risk (pooled age-adjusted $\mathrm{RR}=1.11,95 \% \mathrm{CI}: 0.87-1.43$ and multivariate $\mathrm{RR}=1.12,95 \%$ CI: $0.86-1.44)$ comparing $\geqslant 30$ to $0 \mathrm{~g} \mathrm{day}^{-1}$ (Table 2). There was no significant between-studies heterogeneity $(P$-value, test for between-studies heterogeneity $>0.50)$. Likewise, no association was observed for alcohol from individual beverages and ovarian cancer risk (Table 3). Results were similar after excluding nondrinkers (data not shown).

The nonparametric regression curve also showed no association with alcohol intake and ovarian cancer risk (test for linearity, $P>0.05$ ) (data not shown). Among the five studies that assessed alcohol intake in validation studies (Giovannucci et al, 1991; Munger et al, 1992; Goldbohm et al, 1994; Flagg et al, 2000; Wolk et al, personal communication), the pooled age and energyadjusted relative risk for an increment of $15 \mathrm{~g} \mathrm{day}^{-1}$ of alcohol (equivalent to approximately one serving of alcohol) changed from 1.01 (95\% CI: $0.91-1.11)$ to 1.04 (95\% CI: $0.92-1.18$; $P$-value, test for between studies heterogeneity $=0.91$ ) after correction for measurement error in the assessment of alcohol consumption. For all cohorts, the pooled multivariate RR for this increment was 1.01 (95\% CI: $0.93-1.11)$. In analyses that simultaneously adjusted for intakes of alcohol from wine, beer, and spirits as continuous variables (increment $=15 \mathrm{~g} \mathrm{day}^{-1}$ ), we found no association of alcohol from wine (pooled multivariate $\mathrm{RR}=1.07$, 95\% CI: 0.95 1.21 ), beer (pooled multivariate $\mathrm{RR}=1.02,95 \% \mathrm{CI}: 0.84-1.24$ ) and spirits (pooled multivariate $\mathrm{RR}=1.03,95 \% \mathrm{CI}$ : $0.93-1.14$ ) with ovarian cancer risk ( $P$-value for the test of difference $=0.83$ ). These results were similar to those not mutually adjusted for intake of alcohol from other beverages.

Risk estimates for total alcohol intake were similar for endometrioid $(N=260$, pooled multivariate $\mathrm{RR}=1.05,95 \% \mathrm{CI}$ : $0.87-1.26)$, mucinous $(N=121$, pooled multivariate $\mathrm{RR}=1.06$, 95\% CI: $0.84-1.34)$ and serous $(N=981$, pooled multivariate $\mathrm{RR}=1.07,95 \%$ CI: $0.98-1.17)$ ovarian cancers ( $P$-value for difference by histological type $=0.98$ ).

The association between total alcohol intake and ovarian cancer risk was not modified by hormonal, environmental and nutritional factors (Table 4). The relative risks for total alcohol did not differ 
Table 2 Study-specific and pooled multivariate ${ }^{a}$ adjusted relative risks and $95 \%$ confidence intervals for ovarian cancer according to intake of total alcohol

\begin{tabular}{|c|c|c|c|c|c|c|c|}
\hline \multirow[b]{2}{*}{ Study } & \multicolumn{5}{|c|}{ Categories of alcohol intake $\left(\mathrm{g} \mathrm{day}^{-1}\right)$} & \multirow[b]{2}{*}{$P_{\text {Heterogeneity }}{ }^{\mathrm{c}}$} & \multirow[b]{2}{*}{$P_{\text {trend }}{ }^{d}$} \\
\hline & 0 & $1-4.9$ & $5-14.9$ & $15-29.9$ & $\geqslant 30$ & & \\
\hline Canadian National Breast Screening Study & 1.00 (Ref) & $0.90(0.61-1.33)$ & $1.21(0.81-1.80)$ & $1.10(0.67-1.81)$ & $1.27(0.7 \mathrm{I}-2.25)$ & & 0.24 \\
\hline Cancer Prevention Study II Nutrition Cohort & 1.00 (Ref) & $1.07(0.8 I-1.4 I)$ & $0.85(0.59-1.22)$ & $0.82(0.43-1.53)$ & $0.79(0.39-1.58)$ & & 0.25 \\
\hline lowa Women's Health Study & 1.00 (Ref) & $1.28(0.94-1.75)$ & $0.87(0.53-1.41)$ & $0.71(0.31-1.64)$ & $0.75(0.30-1.88)$ & & 0.24 \\
\hline Nurses' Health Study(a) & I.00 (Ref) & $0.90(0.58-1.40)$ & $0.82(0.49-1.36)$ & $0.92(0.44-1.9 \mid)$ & $0.78(0.32-1.87)$ & & 0.57 \\
\hline Nurses' Health Study(b) & 1.00 (Ref) & $1.13(0.86-1.50)$ & $0.85(0.60-1.20)$ & $1.52(1.01-2.29)$ & $0.87(0.49-1.56)$ & & 0.96 \\
\hline Nurses' Health Study II & I.00 (Ref) & $0.94(0.52-1.72)$ & $0.73(0.29-1.83)$ & $0.60(0.08-4.50)$ & $1.59(0.21-12.1)$ & & 0.84 \\
\hline Swedish Mammography Cohort ${ }^{\mathrm{b}}$ & 1.00 (Ref) & $1.04(0.80-1.35)$ & $1.04(0.68-1.59)$ & $1.19(0.29-4.85)$ & - & & 0.79 \\
\hline Women's Health Study & 1.00 (Ref) & $0.78(0.48-1.27)$ & $1.10(0.65-1.87)$ & $1.04(0.43-2.49)$ & $1.66(0.64-4.32)$ & & 0.21 \\
\hline Cases & 754 & 729 & 320 & 122 & 76 & 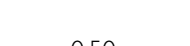 & \\
\hline
\end{tabular}

a Multivariate relative risks were adjusted for calendar year age at menarche $(<13,13,>13$ years), menopausal status at baseline (premenopausal, postmenopausal, dubious), oral contraceptive use (ever, never), hormone replacement therapy use among postmenopausal women (never, past, current), parity $(0,1,2,>2$,), body mass index ( $<23,23-$ $<25,25-<30, \geqslant 30 \mathrm{~kg} \mathrm{~m}^{-2}$ ), smoking status (never, past, current), physical activity (low, medium, high), and energy intake (continuous). 'ंSwedish Mammography Cohort was not included in the category $\geqslant 30 \mathrm{~g}$ of alcohol since this study had no cases in that category. The participants who were not cases who would have been in this highest category were included in the next highest category $\left(15-29.9 \mathrm{gday}^{-1}\right)$. ${ }^{\mathrm{C}} \mathrm{P}$-value, test for between-studies heterogeneity is for the $\geqslant 30 \mathrm{~g}$ day ${ }^{-1}$ category. ${ }^{\mathrm{d}} \mathrm{P}$-value, test for trend.

Table 3 Pooled age and multivariate ${ }^{a, b}$ adjusted relative risks (RR) and 95\% confidence intervals (Cl) for ovarian cancer according to intake of alcohol from specific beverages

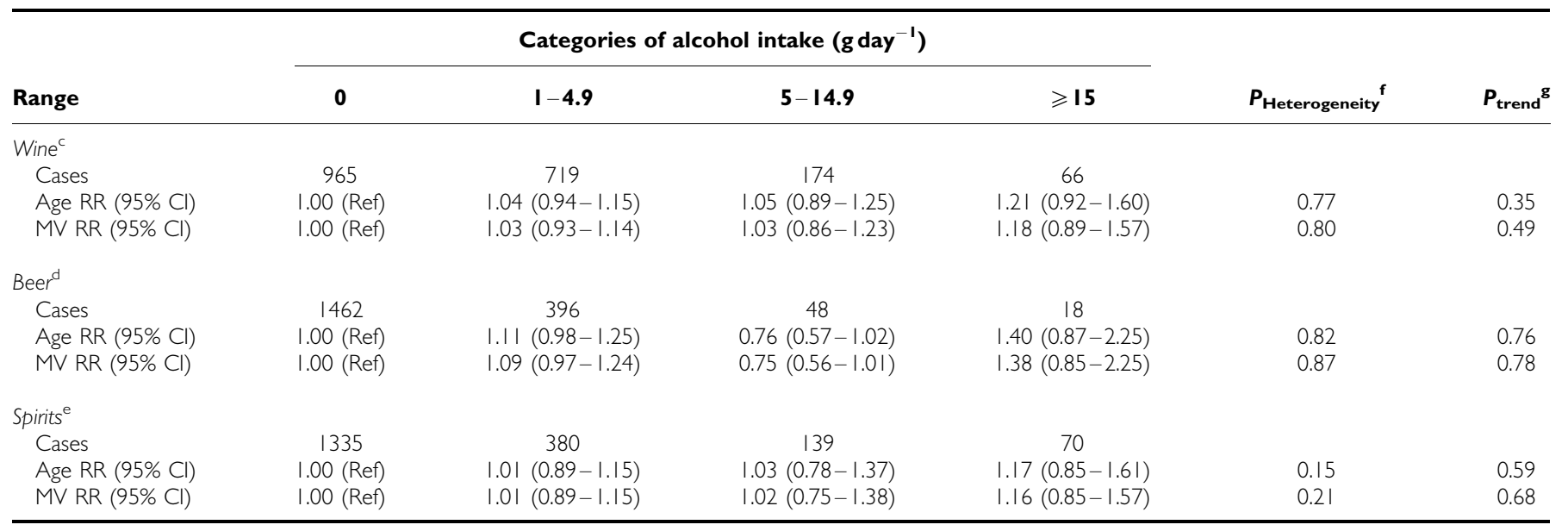

${ }^{a}$ Age adjusted relative risks were adjusted for age and calendar year. Multivariate relative risks were adjusted for the same covariates as the multivariate model in Table 2. In these analyses, alcohol from wine, beer and spirits were not mutually adjusted. ${ }^{b} \mathrm{New}$ York State Cohort was not included in these analyses because they did not measure consumption of alcohol from specific beverages. 'Nurses' Health Study II was not included in the $5-14.9$ and $\geqslant 15 \mathrm{~g}$ day ${ }^{-1}$ categories of alcohol from wine since this study had no cases in that category. 'Nurses' Health Study II and Swedish Mammography Cohort were not included in the $\geqslant 15 \mathrm{~g} \mathrm{day}^{-1}$ category of alcohol from beer since these studies had no cases in that category. The participants who were not cases who would have been in this highest category were included in the next highest category $\left(5-14.9 \mathrm{~g} d a y{ }^{-1}\right)$. ${ }^{\text {eSwedish }}$ Mammography Cohort was not included in the $\geqslant 15 \mathrm{~g} \mathrm{day}^{-1}$ category of alcohol from spirits since this study had no cases in that category. ${ }^{f} P$-value, test for between-studies heterogeneity is for $\geqslant 15$ gday $^{-1}$ category. ${ }^{g} P$-value, test for trend.

when the cases were stratified into two groups defined by age at diagnosis (data not shown). Sensitivity analyses in which we limited analyses to the first 6 years of follow-up compared to six or more years of follow-up showed similar results to the overall result (data not shown).

\section{DISCUSSION}

In this pooled analysis of prospective studies, no statistically significant associations were observed for alcohol intake overall, or from specific beverages, with ovarian cancer risk. In contrast to the inverse results published in a recent meta-analysis (Webb et al,
2004) of five population-based case-control and two cohort studies, our null results were similar to those reported in three recently published population-based case-control studies (McCann et al, 2003; Modugno et al, 2003; Riman et al, 2004) and in the meta-analysis (Webb et al, 2004) of seven hospital-based case-control studies. Unlike two case-control studies (Goodman and Tung, 2003; Webb et al, 2004), we did not observe an inverse association between wine intake and ovarian cancer risk.

Two case-control studies have examined alcohol intake in relation to serous, mucinous, and endometrioid ovarian cancers risk separately (Kuper et al, 2000; Modugno et al, 2003). One study saw a higher risk of mucinous ovarian cancer with higher alcohol intake (Modugno et al, 2003). In contrast, we found no difference 
Table 4 Pooled multivariate relative risks $\mathrm{a}^{\mathrm{a}}$ and $95 \%$ confidence intervals for a $15 \mathrm{~g} \mathrm{day}^{-1}$ increment in total alcohol intake by levels of other ovarian cancer risk factors, continuous model

\begin{tabular}{|c|c|c|c|}
\hline Factor & Cases & $\begin{array}{c}\text { Relative risk } \\
(95 \% \mathrm{Cl})\end{array}$ & $\begin{array}{c}\text { P-value, } \\
\text { test for } \\
\text { interaction }\end{array}$ \\
\hline \multicolumn{4}{|l|}{ Hormonal/reproductive } \\
\hline \multicolumn{4}{|l|}{ Parity (live birth) } \\
\hline$\leqslant 1$ & 518 & $1.02(0.88-1.20)$ & \\
\hline$>1$ & 1435 & $1.02(0.94-1.12)$ & $>0.99$ \\
\hline \multicolumn{4}{|c|}{ Oral contraceptive use $\mathrm{e}^{\mathrm{b}}$} \\
\hline Never & 1124 & $1.02(0.88-1.18)$ & \\
\hline Ever & 599 & $1.05(0.96-1.16)$ & 0.41 \\
\hline \multicolumn{4}{|c|}{ Hormone replacement therapy ${ }^{\mathrm{c}, \mathrm{d}}$} \\
\hline Never & 634 & $1.02(0.84-1.23)$ & \\
\hline Past & 239 & $1.19(0.99-1.44)$ & \\
\hline Current & 211 & $1.10(0.90-1.35)$ & 0.39 \\
\hline \multicolumn{4}{|c|}{ Menopausal status at diagnosis ${ }^{\mathrm{e}}$} \\
\hline Premenopausalf & 140 & $0.72(0.39-1.32)$ & \\
\hline Postmenopausal $^{g}$ & $130 \mid$ & $1.05(0.94-1.16)$ & 0.24 \\
\hline \multicolumn{4}{|l|}{ Nutritional } \\
\hline \multicolumn{4}{|c|}{ Methionine intake (median) } \\
\hline Low & 990 & $1.02(0.94-1.12)$ & \\
\hline High & 1011 & $1.04(0.85-1.26)$ & 0.34 \\
\hline \multicolumn{4}{|c|}{ Folate intake $(\text { median })^{\mathrm{h}}$} \\
\hline Low & 743 & $0.97(0.86-1.09)$ & \\
\hline \multirow{2}{*}{\multicolumn{4}{|c|}{ Multivitamin use ${ }^{i}$}} \\
\hline & & & \\
\hline No & 959 & $1.01(0.90-1.13)$ & \\
\hline Yes & 513 & $1.01(0.83-1.23)$ & 0.56 \\
\hline \multicolumn{4}{|l|}{ Other } \\
\hline \multicolumn{4}{|l|}{ Smoking status ${ }^{j}$} \\
\hline Never & 914 & $0.97(0.84-1.13)$ & \\
\hline Past & 499 & $1.09(0.96-1.23)$ & \\
\hline Current ${ }^{k}$ & 285 & $1.05(0.87-1.28)$ & 0.52 \\
\hline \multicolumn{4}{|c|}{ Body mass index $\left(\mathrm{kg} \mathrm{m}^{-2}\right)$} \\
\hline$\leqslant 23$ & 707 & $1.00(0.90-1.11)$ & \\
\hline $23-<25$ & 416 & $1.06(0.93-1.21)$ & \\
\hline $25-<30$ & 566 & $1.07(0.93-1.23)$ & \\
\hline$\geqslant 30$ & 261 & $1.03(0.80-1.33)$ & 0.74 \\
\hline
\end{tabular}

aMultivariate relative risks were adjusted for the same covariates as the multivariate model in Table 2. Within each model, the stratification variable was excluded from the model. ${ }^{b} \mathrm{New}$ York State Cohort was excluded in this analysis because they did not measure oral contraceptive use on the baseline questionnaire. ${ }^{\mathrm{C}} \mathrm{C}$ anadian National Breast Screening Study, New York State Cohort, and Swedish Mammography Cohort were excluded from this analysis because they did not measure never, past or current hormone replacement therapy use at baseline. 'Netherlands Cohort Study and Nurses' Health Study(a) were excluded from the current hormone replacement therapy use analysis due to small case numbers $(n<10)$. ${ }^{e}$ New York State Cohort was excluded from this analysis because they did not measure menopausal status on the baseline questionnaire. 'Breast Cancer Detection Demonstration Project Follow-up Study, Cancer Prevention Study II Nutrition Cohort, lowa Women's Health Study, Netherlands Cohort Study, and Swedish Mammography Cohort were excluded from the premenopausal analysis due to small case numbers $(n<10)$. ${ }^{8}$ Nurses' Health Study II was excluded from the postmenopausal analysis due to small case numbers $(n<10) .{ }^{h}$ Canadian National Breast Screening Study and Swedish Mammography Cohort were excluded because they folate intake includes dietary and supplemental sources did not have the use of multivitamins and single supplement data available. 'Canadian National Breast Screening Study and Swedish Mammography Cohort were excluded because they did not have use of multivitamin data available. 'Swedish Mammography Cohort was excluded from this analysis because they did not measure smoking at baseline. ${ }^{k}$ Nurses Health Study II was excluded from this analysis due to small case numbers $(n<10)$.

\section{REFERENCES}

Allison PD (1995) Survival analysis using the SAS system; A practical guide. Cary, NC, USA: SAS Institute Inc

Anderson T (1984) Introduction to multivariate statistics. New York, NY, 2nd ed. in the associations between alcohol consumption and the risk of specific histological types of ovarian cancer. Although some misclassification is likely to have occurred in our analyses with regard to classifying cases according to histology, the distribution of cases according to the three main histological types in our study was similar to the percent distribution observed in cancer registries and other studies for the main histological subtypes of ovarian cancer (Scully, 1977; Chen et al, 2003).

As our analyses were conducted using only a baseline FFQ covering recent intake, we were unable to assess changes in intakes of alcohol and other nutrients over time, nor were we able to evaluate lifetime drinking patterns. Only a few studies have addressed these additional ways to examine alcohol drinking habits in relation to ovarian cancer risks and the results have been heterogenous (Tzonou et al, 1984; Goodman and Tung, 2003). Additionally, because we measured adult alcohol intake, we may not have captured the relevant exposure time for ovarian carcinogenesis.

In the studies comprising this pooled analysis, diet was measured prior to diagnosis of ovarian cancer; thus, a cancer diagnosis would not have influenced the reporting of alcohol intake. The strength of our study was our ability to correct for measurement error in alcohol intake. The measurement error corrected risk estimates were similar to the uncorrected results which was expected because the assessments of alcohol intake from the study-specific questionnaires and multiple $24 \mathrm{~h}$ recalls or food records have been shown to be highly correlated (Giovannucci et al, 1991; Munger et al, 1992; Goldbohm et al, 1994; Flagg et al, 2000; Wolk et al, personal communication). In addition, we have previously observed a modest positive association between alcohol intake and breast (Smith-Warner et al, 1998) and colorectal cancer (Cho et al, 2004) risk within the Pooling Project suggesting that misclassification of alcohol intake is not likely to obscure a modest association, although we cannot rule out the possibility of a small effect.

Although our categorization of covariates was predetermined according to how each study assessed the covariates on their questionnaires, one advantage of our study was that we were able to control for covariates uniformly and classify the main exposures similarly, thereby lessening a potential source of heterogeneity across studies. Within our models, we adjusted for most of the important known ovarian cancer risk factors if they were measured in a study. In studies that measured all of the covariates that were included in our multivariate models, results from the age-adjusted and multivariate models were similar suggesting that confounding was minimal. Owing to the inclusion of ten cohort studies, we had far greater statistical power than any individual cohort study to examine whether associations differed for histological subtypes or population subgroups.

In summary, we found no association between intakes of alcohol and alcohol from specific beverages during adulthood and ovarian cancer risk in this pooled analysis. Similarly, we observed no association between alcohol consumption and ovarian cancer risk by histology. Associations with alcohol intake were not modified by risk or preventive factors for ovarian cancer. Thus, this pooled analysis does not provide support for an association between moderate alcohol intake and ovarian cancer risk.

\section{ACKNOWLEDGEMENTS}

This study was supported by grants from the National Institutes of Health, \# CA098566 and \#CA55075.
Bandera EV, Freudenheim JL, Marshall JR, Zielezny M, Priore RL, Brasure J, Baptiste M, Graham S (1997) Diet and alcohol consumption and lung cancer risk in the New York State Cohort (United States). Cancer Causes Control 8: 828-840 
Bertone ER, Rosner BA, Hunter DJ, Stampfer MJ, Speizer FE, Colditz GA, Willett WC, Hankinson SE (2002) Dietary fat intake and ovarian cancer in a cohort of US women. Am J Epidemiol 156: $22-31$

Calle EE, Rodriguez C, Jacobs EJ, Almon ML, Chao A, McCullough ML, Feigelson HS, Thun MJ (2002) The American Cancer Society Cancer Prevention Study II Nutrition Cohort: rationale, study design, and baseline characteristics. Cancer 94: 500-511

Chen VW, Ruiz B, Killeen JL, Cote TR, Wu XC, Correa CN (2003) Pathology and classification of ovarian tumors. Cancer 97: 2631-2642

Cho E, Smith-Warner SA, Ritz J, van den Brandt PA, Colditz GA, Folsom AR, Freudenheim JL, Giovannucci E, Goldbohm RA, Graham S, Holmberg L, Kim DH, Malila N, Miller AB, Pietinen P, Rohan TE, Sellers TA, Speizer FE, Willett WC, Wolk A, Hunter DJ (2004) Alcohol intake and colorectal cancer: a pooled analysis of 8 cohort studies. Ann Inter Med 140: 603-613

Cochran WG (1954) The combination of estimates from different experiments. Biometrics 10: $101-129$

Cox DR (1972) Regression models and life-tables. J R Statist Soc, Series (B) 34: $187-220$

Cramer DW, Welch WR (1983) Determinants of ovarian cancer risk. II. Inferences regarding pathogenesis. J Nat Cancer Institute 71: 717-721

DerSimonian R, Laird N (1986) Meta-analysis in clinical trials. Controlled Clin Trials 7: $177-188$

Durrleman S, Simon R (1989) Flexible regression models with cubic splines. Statist Med 8: $551-561$

Epicure software (1993) EPICURE user's guide: the PEANUTS program. Seattle: Hirosoft

Flagg EW, Coates RJ, Calle EE, Potischman N, Thun MJ (2000) Validation of the American Cancer Society Cancer Prevention Study II Nutrition Survey Cohort Food Frequency Questionnaire. Epidemiology 11: 462-468

Gavaler JS, van Thiel DH (1992) Hormonal status of postmenopausal women with alcohol-induced cirrhosis: further findings and a review of the literature. Hepatology 16: 312-319

Giovannucci E, Colditz G, Stampfer MJ, Rimm EB, Litin L, Sampson L, Willett WC (1991) The assessment of alcohol consumption by a simple self-administered questionnaire. Am J Epidemiol 133: 810-817

Goldbohm RA, van den Brandt PA, Brants HA, van't Veer P, Al M, Sturmans F, Hermus RJ (1994) Validation of a dietary questionnaire used in a large-scale prospective cohort study on diet and cancer. Eur J Clin Nutr 48: $253-265$

Goodman MT, Tung KH (2003) Alcohol consumption and the risk of borderline and invasive ovarian cancer. Obstet Gynecol 101: 1221-1228

Kelemen LE, Sellers TA, Vierkant RA, Harnack L, Cerhan JR (2004) Association of folate and alcohol with risk of ovarian cancer in a prospective study of postmenopausal women. Cancer Causes Control 15: $1085-1093$

Kuper H, Titus-Ernstoff L, Harlow BL, Cramer DW (2000) Population based study of coffee, alcohol and tobacco use and risk of ovarian cancer. Int J Cancer 88: 313-318

Lacey Jr JV, Mink PJ, Lubin JH, Sherman ME, Troisi R, Hartge P, Schatzkin A, Schairer C (2002) Menopausal hormone replacement therapy and risk of ovarian cancer. JAMA 288: $334-341$

Larsson SC, Giovannucci E, Wolk A (2004) Dietary folate intake and incidence of ovarian cancer: the Swedish Mammography Cohort. J Natl Cancer Inst 96: 396-402

Lin J, Zhang SM, Cook NR, Lee IM, Buring JE (2004) Dietary fat and fatty acids and risk of colorectal cancer in women. Am J Epidemiol 160: 1011 - 1022

McCann SE, Freudenheim JL, Marshall JR, Graham S (2003) Risk of human ovarian cancer is related to dietary intake of selected nutrients, phytochemicals and food groups. J Nutr 133: 1937-1942
Modugno F, Ness RB, Allen GO (2003) Alcohol consumption and the risk of mucinous and nonmucinous epithelial ovarian cancer. Obstet Gynecol 102: $1336-1343$

Munger RG, Folsom AR, Kushi LH, Kaye SA, Sellers TA (1992) Dietary assessment of older Iowa women with a food frequency questionnaire: nutrient intake, reproducibility, and comparison with 24-h dietary recall interviews. Am J Epidemiol 136: 192-200

Percy C, Van Holten V, Muir C (1990) International Classification of Diseases for Oncology, Vol. 2. Geneva: World Health Organization

Poschl G, Seitz HK (2004) Alcohol and cancer. Alcohol Alcoholism 39: $155-165$

Riman T, Nilsson S, Persson IR (2004) Review of epidemiological evidence for reproductive and hormonal factors in relation to the risk of epithelial ovarian malignancies. Acta Obstet Gynecol Scand 83: $783-795$

Rockhill B, Willett WC, Hunter DJ, Manson JE, Hankinson SE, Spiegelman D, Colditz GA (1998) Physical activity and breast cancer risk in a cohort of young women. J Natl Cancer Inst 90: 1155-1160

Rosner B, Spiegelman D, Willett WC (1990) Correction of logistic regression relative risk estimates and confidence intervals for measurement error: the case of multiple covariates measured with error. $\mathrm{Am} J$ Epidemiol 132: $734-745$

Rosner B, Willett WC, Spiegelman D (1989) Correction of logistic regression relative risk estimates and confidence intervals for systematic within-person measurement error. Statist Med 8: 1051-1069

Schouten LJ, Zeegers MP, Goldbohm RA, van den Brandt PA (2004) Alcohol and ovarian cancer risk: results from the Netherlands Cohort Study. Cancer Causes Control 15: 201-209

Scully RE (1977) Ovarian tumors. A review. Am J Pathol 87: 686-720

Smith PL (1979) Splines as a useful and convenient statistical tool. Am Statist 33: 57-62

Smith-Warner S, Spiegelman D, Ritz J, Albanes D, Beeson W, Bernstein L, Berrino F, van den Brandt P, Buring J, Cho E, Colditz G, Folsom A, Freudenheim J, Giovannucci E, Goldbohm R, Graham S, Harnack L, Horn-Ross P, Krogh V, Leitzmann M, McCullough M, Miller A, Rodriguez C, Rohan T, Schatzkin A, Shore R, Virtanen M, Willett W, Zeleniuch-Jacquotte A, Zhang S, Hunter D. Methods for Retrospective Pooling of Results of Studies: the Pooling Project of Prospective Studies of Diet and Cancer. Am J Epidemiol, in press

Smith-Warner SA, Spiegelman D, Yaun S-S, van den Brandt PA, Folsom AR, Goldbohm RA, Graham S, Holmberg L, Howe GR, Marshall JR, Miller AB, Potter JD, Speizer FE, Willett WC, Wolk A, Hunter DJ (1998) Alcohol and breast cancer in women: a pooled analysis of cohort studies. J Am Med Assoc 279: 535-540

Terry PD, Miller AB, Jones JG, Rohan TE (2003) Cigarette smoking and the risk of invasive epithelial ovarian cancer in a prospective cohort study. Eur J Cancer 39: $1157-1164$

Tzonou A, Day NE, Trichopoulos D, Walker A, Saliaraki M, Papapostolou M, Polychronopoulou A (1984) The epidemiology of ovarian cancer in Greece: a case-control study. Eur J Cancer Clin Oncol 20: 1045-1052

Verkasalo PK, Thomas HV, Appleby PN, Davey GK, Key TJ (2001) Circulating levels of sex hormones and their relation to risk factors for breast cancer: a cross-sectional study in 1092 pre- and postmenopausal women (United Kingdom). Cancer Causes Control 12: 47-59

Webb PM, Purdie DM, Bain CJ, Green AC (2004) Alcohol, wine, and risk of epithelial ovarian cancer. Cancer Epidemiol Biomarkers Prev 13: $592-599$

Wolk A, Lundkvist B, Spiegelman D, Hunter D, Adami H-O. Effects of various assumptions about portion sizes and nutrient composition on validity of a food frequency questionnaire. (personal communication) 